\title{
A Rare Case Report on Primary Aneurysmal Bone Cyst of the Patella
}

\section{IJCRR}

Section: Healthcare

Sci. Journal Impact

Factor: 6.1 (2018)

ICV: $90.90(2018)$

(c) (i) (3)

Copyright@IJCRR

\section{Suvarn Gupta1, Ankush Mohabey², Vasant Gawande ${ }^{3}$, Kunal Saoji2, Ashwin Chauhan ${ }^{4}$, Ashutosh Parate ${ }^{5}$, Aakash Sharma ${ }^{5}$}

\begin{abstract}
'Assistant Professor, Department of Orthopaedics, Jawaharlal Nehru Medical College, Wardha, M.S., India; 'Assistant Professor, Department of

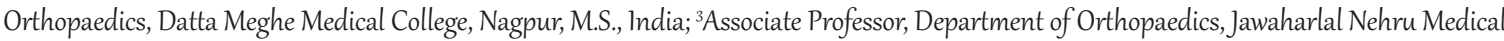
College, Wardha, M.S., India; ${ }^{5}$ Senior Resident, Department of Orthopaedics, Jawaharlal Nehru Medical College, Wardh, M.S., India; 5 Junior Resident, Department of Orthopaedics, Datta Meghe Medical College, Nagpur, M.S., India.
\end{abstract}

\section{ABSTRACT}

Introduction: Aneurysmal bone cysts constitute less than $1 \%$ of primary bone tumours in humans and are usually present in the region of the metaphysis of the long bones of the leg. Less than $1 \%$ of all aneurysmal cysts involves patella. We are reporting a case of primary aneurysmal bone cyst in the right patella in a 27-year-old man treated with excisional curettage and bone grafting with cementing. At the 1 year follow-up, the patient was pain-free with a full range of motion of the knee joint.

Aim: Primary aneurysmal bone cyst of the patella.

Result: The clinical examination and history did not suggest any recent trauma or signs of inflammation. Tenderness was present in the patella and there was knee swelling as compared to the contralateral side.

Conclusion: Local examination revealed tenderness in the patella and irregular, supra-patellar, infra-patellar and para-patellar fullness in the anterior aspect of the knee, with a full range of motion of the join.

Key Words: Aneurysmal Cyst; Patella; Curettage, Aneurysmal cysts, Knee joint

\section{INTRODUCTION}

An aneurysmal bone cyst is a benign tumour with unknown pathophysiology as described by Jaffe and Lichtenstein ${ }^{1}$. $\mathrm{ABC}$ most commonly presents during their second decade of life and mostly involves metaphysis of long bones, followed by spine and sacrum and smaller bone involvement is usually rare. Although benign, the $\mathrm{ABC}$ can be locally aggressive and can cause extensive weakening of the bony structure and impinge on the surrounding tissues. It comprises of less than $1-2 \%$ of all tumours originating from bone. ${ }^{2-5}$. Development of Aneurysmal cyst in the patella is rare $(<1 \%) .{ }^{6-9}$ Exicision alcurettageofthecystandfilling of the defect with a bone graft or cementing ${ }^{10-13}$ is the treatment of choice. Treatment with adjuvants such as phenol and cryotherapy is also advised by some studies. ${ }^{14-16}$ Embolisation or patella ectomy is considered in significant involvement of the patella with articular surface destruction. ${ }^{17-19} \mathrm{We}$, hereby, report a rare case of a primary aneurysmal bone cyst of the patella in a 27 -year-old man.

\section{OBSERVATION}

A male patient aged 27 years consulted in January 2019 with complaints of pain and swelling in the right knee since the last 6 months and intensity of pain was aggravated since 1 month. The clinical examination and history did not suggest any recent trauma or signs of inflammation. Tenderness was present in the patella and there was knee swelling as compared to the contralateral side. Local examination revealed tenderness in the patella and irregular, supra-patellar, infra-patellar and para-patellar fullness in the anterior aspect of the knee, with a full range of motion of the joint.

The haematological evaluation was completely normal. Standard Anteroposterior and lateral Radiographs showed images of diffuse osteolytic lesions with smooth borders occupying more than half of patella within tact articular surface (Fig. 1).

\section{Corresponding Author:}

Dr. Suvarn Gupta, Assistant Professor, Department of Orthopaedics, Jawaharlal Nehru Medical College, Wardha, M.S., India.

ISSN: 2231-2196 (Print) ISSN: 0975-5241 (Online)

Received: 10.06 .2020

Revised: 12.07 .2020

Accepted: 11.08 .2020

Published: 22.08 .2020 

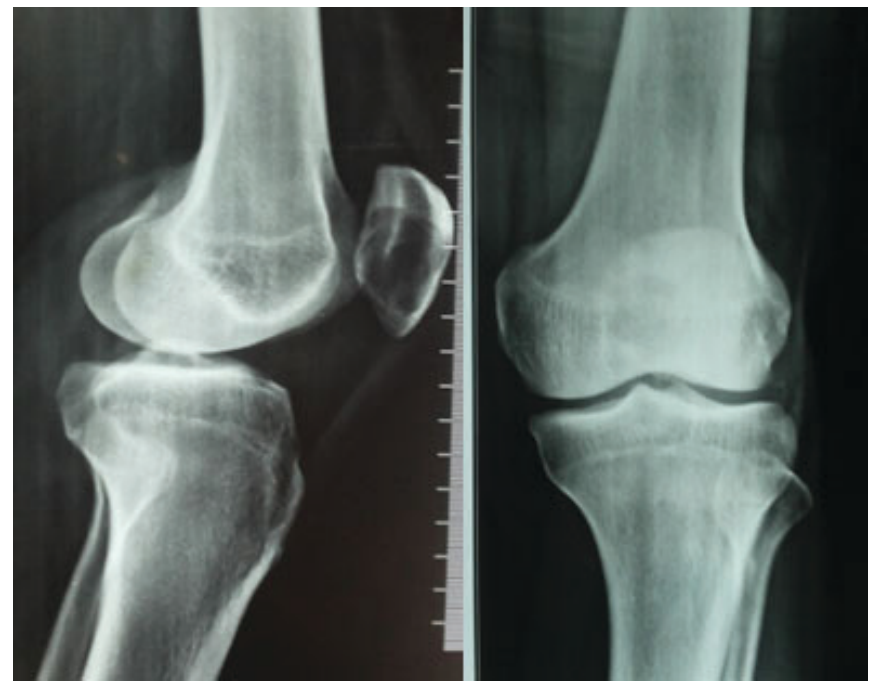

Figure 1: Antero-Posterior and Lateral Radiograph showing diffuse osteolytic lesions with smooth borders occupying more than half of patella leaving the articular surface intact.

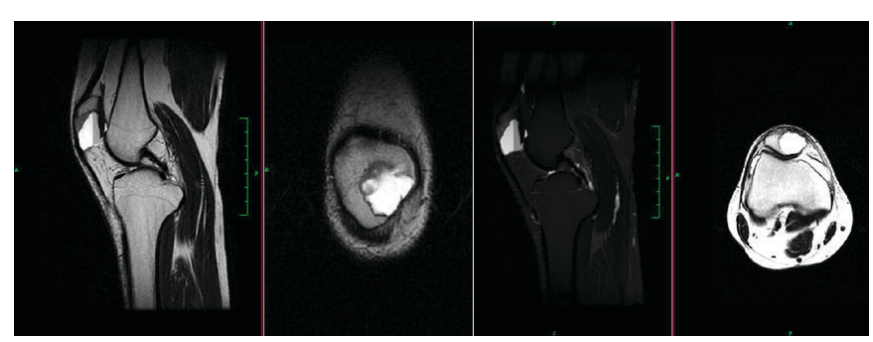

Figure 2: Magnetic resonance images showing multiloculated cysts with fluid-fluid levels in the patella. The lesion had intermediate-to-low signal intensity on the T1-weighted image and high signal intensity on the T2-weighted image.

The absence of intralesional calcifications and the presence of multi-septate cavities with the fluid-fluid level on MRI hinted towards the diagnosis of an aneurysmal bone cyst. Biopsy of the lesion showed features suggestive of Aneurysmal Bone Cyst. Best Treatment option was intralesional curettage and a filling of defect with cortico-cancellous bone graft and cement. A mid-line parapatellar approach was used, the patella was retracted. The articular surface was found to be intact, intralesional curettage with cauterization was done and the bony defect was filled with Polymethyl Metha Acrylate (PMMA) cement and bone graft. Curettage was sent for Histo-pathological examination depicted empty bloody cavities or the presence of red blood cells and the diagnosis of Aneurysmal bone cyst was confirmed (Shown in Fig 1).

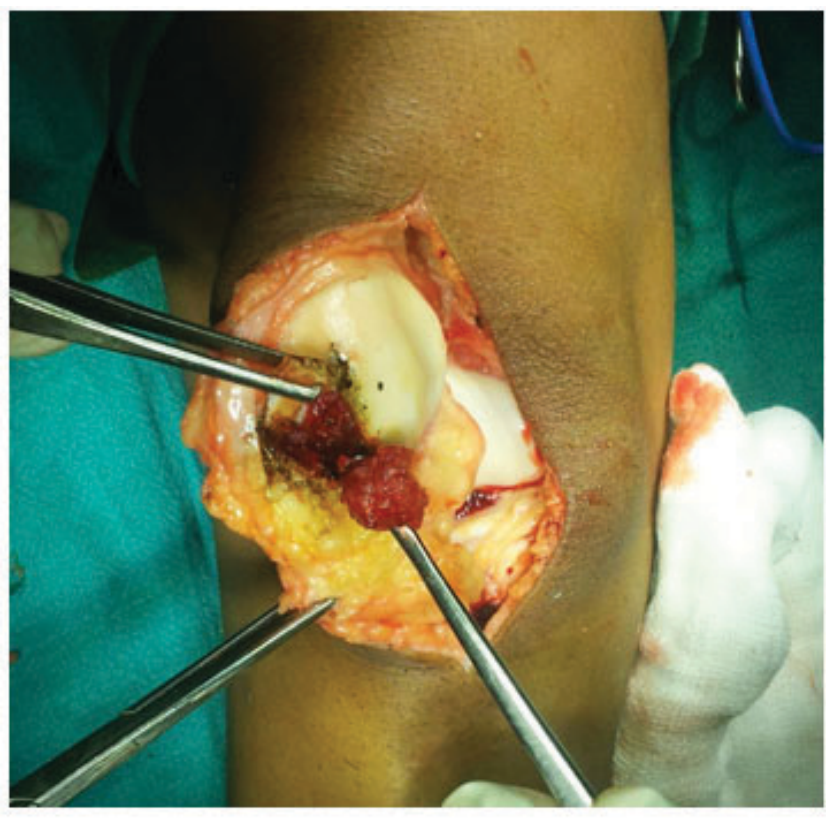

Figure 3: Showing intraoperative photograph of retracted with intact articular surface and blood filled cystic cavity.
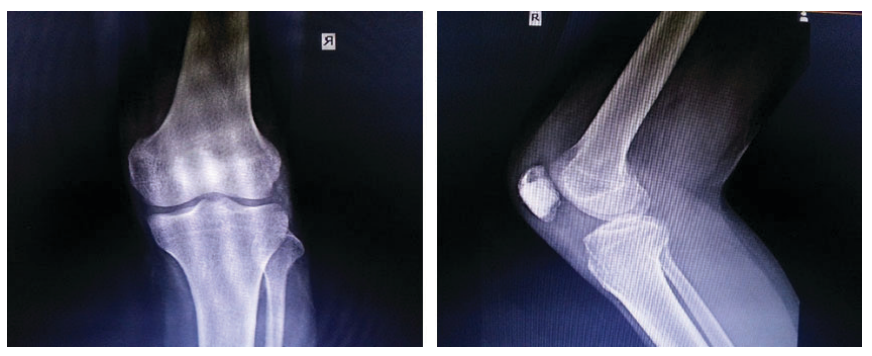

Figure 4 and 5: Showing post-operative radiograph depicting aneurysmal bone cyst patella filled with cement and bone graft.

Postoperatively the cylindrical cast was advised to immobilize the knee joint for 4 weeks. It was followed by a joint range of motion exercises and full weight-bearing walking. At the end of 1year follow-up, the patient was completely pain-free with full knee range of motion (Shown in Fig no 4 and 5).

\section{DISCUSSION}

Tumour of bones involving patella are rare and are mostly benign. Aneurysmal Cysts in patella is a rare entity. ${ }^{2,5,6,7}$ The classical presentation may be a bone lesion having separate multi-septate cavities occurring around the second decade of life or it can be secondary to a traumatic cause or in association with primary tumorlike, giant cell tumour or osteosarcoma or chondroblastoma. 
Clinical presentation usually includes pain in movements and tenderness over patella may or may not be associated with loss of functional range of movements. The pathological fracture may be associated in case of extensive bony involvement. ${ }^{7}$ Standard Radiographs shows an osteolytic lesion involving the patella. MRI confirms the presence of multicystic fluid-filled cystic cavities. The fluid gives intensified signals on T2 weighted images of MRI. ${ }^{4,17}$ The similar findings of X-ray and MRI were present in our case.

One of the differential diagnosis can telangiectatic osteosarcoma in which MRI findings are similar to an aneurysmal cyst. The fluid levels and multiseptate picture can also be present. ${ }^{17-19}$ Hence, a biopsy is mandatory to rule out another differential diagnosis.

Treatment of Aneurysmal bone cysts depends upon the involvement of the bone. The usual treatment of choice is curettage of the cyst and bone grafting with or without cementing $4,9,11,14,16$. The use of adjuvants like phenol or cryotherapy can reduce the chances of recurrence. ${ }^{8}$ According to literature, in the initial day's patellectomy, was thought to be an option. ${ }^{10,11,15}$ But, patellectomy is not advised before attempting for primary patellar reconstruction. In our case, excisional curettage and bone grafting with cementing was done which resulted in good outcome after 1 year of followup. Extensive Curettage of the cyst and bone grafting with cancellous grafts results in a good outcome. In recent literature, minimal cases of recurrence of Aneurysmal cysts were noted.$^{6-11}$

\section{CONCLUSION}

In our case, excisional curettage and bone grafting with cementing was done which resulted in good outcome after 1 year of follow-up. Extensive Curettage of the cyst and bone grafting with cancellous grafts results in a good outcome.

Acknowledgement: Nil

\section{Conflict of interest: Nil}

Source of Funding: Nil

\section{REFERENCES}

1. Jaffe HL, Liechtenstein L. Solitary unicameral bone cyst, with emphasis on the Roentgen picture, the pathologic appearance and pathogenesis. Arch Surg.1942;44:1004-1025.

2. Singh J, James SL, Kroon HM, Woertler K, Davies AM. Tumour and tumour-like lesions of the patella- a multicentre experience. Euro Radiol.2009;19:701-12.

3. Kransdorf MJ, Sweet DE. Aneurysmal bone cyst: concept, controversy, clinical, presentation, and imaging. Asi J. Rea.. 1995; 164:573-80.

4. Chen LK, Chen HY, Perng HL, Wu CC, Tsai YF, Su CT, et al. Imaging features and review literature of aneurysmal bone cyst. Chin J Radiol2005;30:269-375.

5. Oh JH, Kim HH, Gong HS, Lee SL, Kim JY, Kim WS. Primary aneurysmal bone cyst of the patella: a case report. J OrthopSurg.2007;15:234-7.

6. Somasehar RS, Venkata RS. Primary aneurysmal bone cyst of the patella. Indian J Orthop2009;43:216-7.

7. Louaste J, Amhajji L, Chkoura M, Rachid K. Fracture pathologique de la patella sur kysteanévrismalosseux. À propos d'un cas. Rev Chir Orthop. 2008;94:599-603.

8. Castro MD, Irwin RB. Aneurysmal bone cyst of the patella. Am Orthop.1996;25:717-9.

9. Faris WF, Rubin BD, Fielding WJ. Aneurysmal bone cyst of the patella. A case report. J Bone Joint Surg. 1978;60A:711.

10. Copeland CX, Enneking WJ, Robbins WJ. Aneurysmal bone cyst of the patella. A report of two cases. Clin Orthop.1966;45:145-50.

11. Grillo G, Fazioli F, Ruosi C. Cistios sea aneurismati cadella rotula: contributocastico. Chir Organi Mov. 1988;73:171-3.

12. Desnoyers v, Charissoux JL, Arnaud JP. Kysteanévrismal de la rotule. Revue de la litterature a proposd'une observation. Rev Chir Orthop. 2000;86:616-20.

13. Marudanayagam A, Gnanadoss JJ. Secondary aneurysmal bone cyst of the patella: A case report. Iowa Orthop J. 2006; 26: 144 6.

14. Trebse R, Pisot V. Chondroblastoma of the patella associated with aneurismal bone. Acta Orthop Belg. 2001;63:290-6.

15. Gottschalk FA, Solomon L, Isaacson C, Schmaman A. Aneurysmal bone cyst of patella secondary to Chondroblastoma: Case reports. S Afr Med J 1985;67:105-6.

16. Ghekiere J, Geusens E, Lauteur L, Samson I, Sciot R, Baert AL. Chondroblastoma of the patella a secondary aneurismal bone cyst. Euro Radiol.1998;8:992-5.

17. Sullivan RJ, Meyer JS, Dormans JP, Davidson RS. Diagnosing aneurysmal and unicameral bone cysts with magnetic resonance imaging. Clin Orthop Relat Res. 1999;366:186-90.

18. Keenan S, Bui-Mansfield LT. Musculoskeletal lesions with fluid-fluid level: a pictorial essay. J Comput Assist Tomogr 2006;30:517-24.

19. Mercuri M, Casadei R. Patella tumours. Clin Orthop Relat Res. 2001;389:282-7. 